\title{
Investigating Aggression and Its Relationship with Parenting Styles Among Children with Attention Deficit/Hyperactivity Disorder (ADHD) in Zahedan City, 2014
}

\author{
Mahboubeh Firouzkouhi Moghaddam ${ }^{1}$, Marzieh Assareh ${ }^{2}$, Tayebeh Rakhshani ${ }^{3,{ }^{*}}$ and Abbas \\ Broomand $^{1}$ \\ ${ }^{1}$ Research Center for Children and Adolescents, Department of Child and Adolescent Psychiatry, Zahedan University of Medical Sciences, Zahedan, Iran \\ ${ }^{2}$ Department of Psychiatry, Bahonar Hospital, Alborz University of Medical Sciences, Karaj, Iran \\ ${ }^{3}$ Nutrition Research Center, Department of Public Health, Shiraz University of Medical Sciences, Shiraz, Iran \\ "Corresponding author: Nutrition Research Center, Department of Public Health, Shiraz University of Medical Sciences, Shiraz, Iran. Tel: +98-9196250473, Email: \\ trakhshani@gmail.com
}

Received 2018 July 14; Accepted 2018 July 15.

Keywords: Hyperactivity Disorder, Parenting, Aggression, Parents

\section{Dear Editor,}

Attention deficit/hyperactivity disorder (ADHD) is one of the most common psychiatric problems in childhood and adolescence. It can have negative impacts on the social interactions of children and adolescents (1). 5 - 12\% of the children at school age and 3 - 5\% of Iranian primary school children suffer from ADHD (2). These children are less obedient and often less capable of fulfilling their parents' demands (3). Research has shown that aggression is one of the most important attributes of ADHD, and one of the most important factors responsible for its development is the family, especially the parental behavior of patterns. Failure in the treatment of childhood aggression may increase the likelihood of antisocial personality in adulthood $(4,5)$. Considering parenting styles could play a major role in providing children's mental health (6), this study aimed to investigate aggression and its relationship with parenting styles in children with ADHD in Zahedan.

This descriptive cross-sectional study was conducted on 100 children with ADHD, who were 8 to 14 years old and had medical records at Baharan hospital in Zahedan. The parents of the children were investigated, too. The sampling was done through the census. The data collection tools were parenting style inventory and aggressive questionnaire (AGQ) whose validity and reliability had been confirmed in previous studies (7-9).

53 of the children (53\%) were boys and 47 (47\%) were girls. The mean aggression score of the ADHD patients was $49.7 \pm 16.1$ in the range of 18-79. Independent T-test showed there was no significant relationship between parenting styles and children' gender $(\mathrm{P}>0.05)$. The mean score of authoritarian parenting $(26.5 \pm 9.7)$ among the parents of the children with ADHD was higher than the scores of permissive (16.01 \pm 0.45$)$ and authoritative (16.30 \pm 7.04 ) parenting styles. Pearson correlation test showed that there was a significant negative relationship between aggression and permissive $(\mathrm{P}<0.001$ and $\mathrm{r}=-0.51)$ and authoritative $(\mathrm{P}<0.001, \mathrm{r}=-0.81)$ parenting styles and there was a significant direct relationship between aggression and authoritarian parenting styles $(\mathrm{P}<0.001$ and $\mathrm{r}=0.91)$.

Several studies have been conducted on parenting styles among ADHD children; however, there are limited studies on aggression. The results of this study showed that the mean score of aggression among ADHD children was high. However, there was no significant difference in aggression between boys and girls. Therefore, aggression in children with ADHD was not gender-dependent.

Biederman et al. in the United States surveyed aggression in 197 children with ADHD and 224 healthy children. The results showed that $66 \%$ of ADHD children had aggressive behaviors (10). King et al. (2010) in Sweden conducted a study and defined the ADHD-related aggressive subtypes, identified the individual differences that contributed to aggressive behavior in ADHD children, and addressed the main mechanisms of aggression in ADHD children. They indicated that although aggressive behaviors could be seen in children with ADHD, the reasons were not well known (4). However, the present study showed that parenting styles could be one of the factors causing aggres- 
sion in these children.

The results of the present study showed that aggression was associated with parenting styles so that an increase in authoritarian parenting scores led to the increased rate of aggression in children, and an increase in permissive parenting scores led to the decreased rate of children's aggression. Although ineffective parenting behaviors may be responsive to the behavioral problems of the children with ADHD, they can also play an etiological role in the simultaneous emergence of the behaviors among these children. Family misconduct is one of the causes of ADHD-related behaviors and/or its exacerbation. Therefore, it is suggested teaching proper parenting styles to the parents of ADHD children. The authors would like to thank the Zahedan University of Medical Sciences that supported this research. We are also grateful to the research units for their participation in the survey, supporting our work, and helping us get the results of better quality.

\section{References}

1. Firouzkouhi Moghaddam M, Rakhshani T, Khosravi M. Effectiveness of methylphenidate supplemented by zinc, calcium, and magnesium for treatment of ADHD patients in the city of Zahedan. Shiraz E-Medical Journal. 2016;17(9). doi: 10.17795/semj40019.

2. Firouzkouhi Moghaddam M, Forouzan Nia R, Rakhshani T, Heidaripoor AH, Taravatmanesh S. The effectiveness of parent management training ( PMT ) on anxiety and depression in parents of children with ADHD. Shiraz E-Medical Journal. 2016;17(6). doi: $10.17795 /$ semj38795.
3. Chronis-Tuscano A, Raggi VL, Clarke TL, Rooney ME, Diaz Y, Pian J. Associations between maternal attention-deficit/hyperactivity disorder symptoms and parenting.J Abnorm Child Psychol.2008;36(8):123750. doi: 10.1007/s10802-008-9246-4. [PubMed: 18553132]. [PubMed Central: PMC3715319].

4. King S, Waschbusch DA. Aggression in children with attentiondeficit/hyperactivity disorder. Expert Rev Neurother. 2010;10(10):158194. doi: 10.1586/ern.10.146. [PubMed: 20925473].

5. Firouzkouhi Moghaddam M, Asli F, Rakhshani T, Taravatmanesh S. The Relationship Between Parenting Styles and Aggression in Adolescents of Zahedan City in 2014. Shiraz E-Medical Journal. 2016;17(7-8). doi: 10.17795/semj38515.

6. Moghaddam MF, Validad A, Rakhshani T, Assareh M. Child self-esteem and different parenting styles of mothers: a cross-sectional study. Arch Psychiatry Psychother. 2017;19(1):37-42.

7. Esfandiari H. [Reliability and validation of scale for the measurement parents child rearing practices and relationship its life skills in high schools students Minab]. Hormozgan State Researches Education. 2005:7172. Persian.

8. Cloninger CR. Completing the psychobiological architecture of human personality development: Temperament, character, and coherence. In: Staudinger UM, Lindenberger UER, editors. Understanding human development: Dialogues with lifespan psychology. Boston: Kluwer Academic Publishers; 2003. p. 159-81. doi: 10.1007/978-1-46150357-6_8.

9. Shojaei S, Dehdari T, Nouri J. K. Investigating the predicting factors of aggression in adolescents who are violent computer game users in Qom.7. Qom University of Medical Sciences; 2013. p. 71-9. Persian.

10. Biederman J, Petty CR, Day H, Goldin RL, Spencer T, Faraone SV, et al. Severity of the aggression/anxiety-depression/attention child behavior checklist profile discriminates between different levels of deficits in emotional regulation in youth with attention-deficit hyperactivity disorder. J Dev Behav Pediatr. 2012;33(3):236-43. doi: 10.1097/DBP.ob013e3182475267. [PubMed: 22278125]. [PubMed Central: PMC3319866]. 